November 2010, Vol. 4(1), 19-34.

\title{
Well teachers, well students
}

\author{
Faye McCallum \\ Associate Dean: Teaching and Learning \\ School of Education \\ University of South Australia \\ Mawson Lakes, South Australia
}

\section{Deborah Price}

Lecturer

School of Education

University of South Australia

Mawson Lakes, South Australia

\begin{abstract}
Promoting self-awareness of wellbeing in beginning teachers will contribute to their longevity and productivity. As the profession ages we are faced with the fact that many teachers are retiring, creating some shortages; increased numbers are leaving the profession prematurely; fewer applicants are entering teacher training; and some argue that the current workforce of teachers cannot relate to current students' life worlds. For beginning teachers, this raises issues related to their wellbeing and ability to transition and cope, and also justifiably provides challenges and opportunities for school reform, leadership and curriculum renewal. Additionally, teachers must be able to 'connect' with children and young people if they are to make a difference in their learning, health and wellbeing. In this paper we argue that the retention of teachers is dependent on having a wellbeing strategy in place that clearly identifies inhibiting and enabling strategies. Beginning teachers need to be able to identify such strategies to remain well - for themselves and the future of our children and young people.
\end{abstract}

Note: this article relates to the teaching duties of the authors and involves research on pre-service teachers undertaking teacher education at the University of South Australia. 


\section{Introduction}

Educational discourse for beginning teachers predominantly identifies experiences, qualities and ideas to enable student wellbeing. There also exists in the discourse a persistent focus on student achievement and the desire for them to fulfil their maximum educational potential in order to contribute to society. The link between these two drivers (student wellbeing and student achievement) suggests that the teacher has a role to play, so in this paper we explore the notion that well teachers promote well students. Wellbeing constructs, and conceptual frameworks for both student and teacher wellbeing, identify a number of enabling factors that, we argue, centre on holistic, multidimensional wellbeing. These frameworks acknowledge that, to be well, physical, social, emotional, cognitive and spiritual dimensions need to be valued. Taking responsibility and developing a sense of agency in one's own wellbeing is central to productivity, wellness and a sustained teaching career. Enabling teacher wellbeing experiences demands active participation, consisting of physical activity, cognitive stimulation, social interactions and a connection with significant places. Connectedness and communication are essential to establishing supportive and productive communities. A positive attitude, taking ownership and responsibility, along with identifying as a lifelong learner are qualities that sustain teacher wellbeing and identity. Ideas for enabling teacher wellbeing include working with like-minded people in collaborative endeavours as well as the importance of maintaining a work-life balance.

Wyn (2009) described how wellbeing has become increasingly significant since the 1980s and has moved from a focus on economic, physical health, women's health and children's wellbeing to an emerging focus on individualised responsibility for wellbeing, 'an increasing emphasis on the moral and social responsibility that individuals hold for managing their personal wellbeing at home and at work' (Wyn 2009, p. 7). White and Wyn (2008, p. 223) added that there is widespread interest in the ways in which young people themselves manage to be well and in the role of institutions such as health, education, family and juvenile justice in promoting young people's wellbeing. In a 2007 article, Wyn argued that new social and economic developments may have a deleterious effect on the changing preparation of our young people for the future. The school curriculum, despite some historical foci on health and fitness, fails to provide adequately for a holistic view of health and wellbeing and, in fact, negates the current life worlds of school age children (2007, pp. 35-36). Despite some examples of schools embracing a notion of wellbeing, many fail to address the lifestyle needs of young people. Exacerbating this problem is the capacity for teachers to address the needs of young people in changing times and to prepare them adequately for the uncertainties of the future. These factors, which can be more pronounced for beginning teachers, influence teacher wellbeing and ultimately the wellbeing of students. In order for teachers and educational leaders to have a positive impact on the wellbeing of students' lives, to model good practice in wellbeing, and to assist young people to prepare for the future as they transition through schooling, they must be well themselves.

Teacher retention and attrition is a global concern. As Moon (2007, pp. 25-27) reported, the number of full-time equivalent teachers leaving the profession has increased in recent years. For example, in the UK, of the approximately 10 per cent 
of teachers who left in 2003/04, 25 per cent retired (many were in leadership posts) and the remainder moved out of the service altogether. He claimed that there are problems attracting entrants to teaching, with some specialist areas already in crisis. Ross and Hutchings (2003, p. 30) claimed that the greying of the teaching force means there is a high and increasing turnover of head teachers and the cohort to replace those in leadership positions is small. Farber (1991, cited in Hakanen, Bakker and Schaufeli 2006) estimated that between 5 per cent and 20 per cent of United States teachers are burned out and the significance of this is that teacher stress and burnout affect the schools' study climate, lower morale, prevent the attainment of educational objectives, and increase the probability of teachers leaving their posts. Yong and Yue (2007, p. 79) claimed that this has a flow-on effect on students in schools.

In Australia, as in other industrialised countries, the status of teachers is declining too (Louden 2008; Moon 2007). The increased focus on standards, while meritorious, inadvertently contributes to increased anxiety in teachers despite teacher education programs and professional development aimed at addressing this pressure. In South Australia, Hugo (2007) found that teaching was seen as a shortterm career by beginning teachers and teacher stress and heavy workload explain why many young teachers leave within their first five years. Hugo found the following issues to have a negative impact on new teachers: increased global competition for talent (better pay and conditions, better promotional opportunities); increased emphasis on human capital (graduates seek higher paid employment); changing occupational patterns (graduates change jobs more frequently); and the increasing demands of the student clientele. We would also add that because teacher salaries peak when young teachers reach their mid 30s there is lack of reward for good performance. Also, there are no clear career paths, work is now more performance based and corporatised, teaching is viewed as a path to other careers, and teachers' long hours are also seen as invisible to the general public, leaving them feeling undervalued and overworked.

The changing nature of teachers' work and how it is regulated and managed within the twenty-first century plays a significant role in job satisfaction. For example, there is an incongruity between demands placed upon teachers and the ability to resource such demands. These include emotional demands (such as student discipline, counselling/social work), social support, performance management, mentoring and organisational leadership. Additionally, the cognitive and emotional effort required for the physical, psychological, social and organisational aspects of teaching may impact on performance especially if these demands are required at a sustained level. Continually evolving pedagogy, policy development, rapid development in the area of ICTs (information and communication technologies), social and political pressure, curriculum, methodology and assessment promotes relentless demands on teachers, even the most dedicated and experienced (Leggo 2005).

Deficit media views can influence perceptions of the teaching profession to such an extent that the negativity can impact on teacher morale. Recent media reports have focused on the impact of large class sizes, the low literacy and numeracy levels of 
children, the perceived increase in disruptive behaviour, individual case studies of students' needs not being met, sexual abuse and harassment cases, inclusion issues, industrial action over poor pay and conditions, the perception that teachers have extensive school holidays, and an assumption that students lack a sense of values and morals. And then there appears to be societal changes in family structure, movement away from a sense of local community with no sense of belonging, and there is globalisation and easier access to worldwide information and communication. These factors demand that education must play a role in promoting a sense of belonging, values-based learning, engaging at-risk students, child protection, social networking and keeping abreast of mass media influences. However, these social and political pressures fuel unrealistic expectations of teachers.

The school macro system and classroom micro system are influenced by a multitude of interpersonal relationships: between teachers, students, parents, support personnel, leadership and community groups. Daily changes in the balance of these relationships place ongoing demands on teachers which ultimately influence the learning environment, behaviour and classroom climate. These interpersonal relationships may contribute to a negative work climate, and lack of support, recognition, trust and respect amongst colleagues, parents, leadership and students (Butt and Retallick 2002).

Continued political and economic issues (for example, the Council of Australian Governments' agenda and the new National Curriculum in Australia) have provoked certain local, national and international challenges for the teaching profession which can contribute to stress, burnout, work overload and job dissatisfaction. These terms are commonly echoed in the literature (Singh and Billingsley 1996, cited in Pillay, Goddard and Wilss 2005) and can lead to a 'range of physical disorders' (Lantieri and Nambiar 2004, p. 121). Teachers may experience burnout (Hakanen, Bakker and Schaufeli 2006; Hart et al. 2000) and, as research has indicated, this can affect the quality of teachers' work and interactions with students. We suggest that a focus on wellbeing during teacher training and in the early years of a teacher's career may be a positive influence for beginning teachers, enabling them to respond to demands in a more positive, productive and beneficial way which will enable the wellbeing of the students with whom they interact.

\section{Wellbeing defined}

Recent studies show that a fifth to a third of young people today experience significant psychological distress or disturbance (Cummins et al. 2002, p. 36). Bernard, Stephanou and Urbach stated:

Four in 10 students worry too much, 3 in 10 students are very nervous/stressed, 2 in 10 students have felt very hopeless and depressed for a week and have stopped regular activities, a third of students lose their temper a lot and are sometimes quite mean to others, two-thirds of students are not doing as well in their schoolwork as they could, and 4 in 10 students have difficulty calming down. (2007, p. 5)

This diminished and often debilitating loss of hope and wellbeing is a reason for making wellbeing a key aspect of teacher education programs. Through this 
promotion, a notion of wellbeing that encompasses all the dimensions (social, emotional, physical, cognitive and spiritual), which is referred to as 'whole person' learning, is needed. Rogers (1980), Berman (1989) and Wilber (2000) consider this to be necessary for personal and community wellbeing. Wellbeing and relationships development emphasises the importance of valuing difference and diversity and is described by Holmes (2005) as a state of being comfortable, healthy and happy. Roberts calls it a 'holistic subjective state which is present when a range of feelings, among them energy, confidence, openness, enjoyment, happiness, calm, and caring, are combined and balanced' (2005, p. 6, quoted in DECS 2007). This state can lead to respecting and developing productive and affirming relationships with adults, peers, other species and physical environments. As a result, young people become empowered by viewing the world critically, experiencing it physically, and then acting independently, cooperatively and responsibly. This promotes 'wellbeing' that encompasses the dimensions of learning.

In this paper we see wellbeing as being systematically developmental, which implies the promotion of positive personal and physical identities as well as a sense of belonging. This approach emphasises how social and cultural forces shape individual and group identities which, we purport, is ideally suited to beginning teachers entering the profession. Such an approach acknowledges that body and mind cannot be separated when it comes to learning (Johnson 1987) even though it is common practice to see them as separate entities.

Contemporary research into teacher wellbeing identifies numerous inhibiting and protective factors, with a focus on resilience. Protective factors, such as managing stress and learning coping skills, are a reaction to a state of unwellness, whereas Van Petegem, Creemers, Rosseel and Aelterman (2006) promote a positive view of wellbeing by focusing on a stable emotional state and a sense of harmony between context and teacher, whereby teachers attune themselves to specific school context factors and demands. This view contributes to effective human relationships based on democracy and agreement. Entwistle added that we also need 'emotional and moral, as well as cognitive sources of satisfaction in schooling' (1987, p. 6, cited in Van Petegem et al. 2006).

The inhibiting factors to teacher wellbeing described here support the view that teacher training must focus on sustained health and wellbeing. We argue that beginning teachers require more than awareness of these risk and protective factors; they should also be skilled with enabling wellbeing strategies.

\section{This study}

A cohort of pre-service teachers at the University of South Australia in the Bachelor of Education: Primary/Middle degree completed a core course in the final semester of their undergraduate degree called 'The Emerging Self: Wellbeing and Identity'. One focus in the course is teacher wellbeing, which is emphasised within the five dimensions of wellbeing (social, emotional, cognitive, physical and spiritual) that form part of the Learner wellbeing framework (DECS 2007). 
The participants from this course engaged in a small research study that focused on beginning teachers' levels of wellbeing. Beginning teachers are defined here as those at the end of their formal undergraduate coursework who have met all university requirements including a minimum of 90 days professional experience in schools. They are eligible for graduation from the program and, once registered by the local Teachers' Registration Board, will begin work as a teacher. Participants $(n=80)$ were aged between 20 and 38 years of age; 22 were male and 58 female. This program (Bachelor of Education: Primary/Middle) was selected as the focus of this study because of its unique design based on seven core principles that are embedded through its teaching and learning framework. Importantly, the wellbeing course is largely influenced by the wellbeing and relationships development principle, described in the program accreditation document as a principle that:

- explores how young peoples' wellbeing can be enhanced through developing positive identities, relationships, purpose (hope), empowerment, success, rigour and safe living;

- prepares young people for roles within complex systems where multiple literacies, and bodily and thinking skills are essential;

- is committed to presenting learning environments that engage multiple perceptual modalities, allowing for broader student learning styles to be accommodated as well as stimulated;

- is committed to a collaborative and teams approach to teaching and learning; and

- challenges students to work together to know and understand young people in their care, and employ powerful pedagogical strategies to extend them within supportive environments.

In this research we employed a qualitative approach to collecting data because we required the participants to identify and then apply their personal and professional state of wellbeing to a holistic wellbeing framework that encompassed the five dimensions. Participants responded to the following focus question: As an emerging teacher consider the issues that influence your wellbeing as you enter the educational setting. Draw on the five dimensions of wellbeing (cognitive, social, emotional, physical and spiritual) and the strategies you will employ to promote your own positive wellbeing. Describe possible outcomes of these strategies. This narrative genre provided them with a free-flowing space in which to think deeply, to reflect and plan. This research methodology is supported by Clandinin (2007) who claimed that narrative ways of studying what goes on in classrooms, schools and teachers' lives is a challenging and unique research journey for many researchers. Participants were emergent thinkers in terms of their personal understandings of teachers' work and how wellbeing enabled them to be fully effective. They also worked closely with the researchers during university classes in the process of learning about this conjuncture. We provided opportunities for both formal and informal sharing of personal stories which, as Witherell and Doddings (1991, p. 1) 
pointed out, enable effectual learning to occur. Stories and metaphors, whether personal or fictional, provide meaning and belonging in our lives. They attach us to others and to our histories by providing a tapestry rich with threads of time, place, character and even advice on what we might do with our lives.

The narrative approach is well suited to the present study. Not only did it allow us to examine teaching, it also enabled us to ask critical questions about teaching in the future (Clandinin 2007, p. 357). It also allowed us to pay attention to teachers, as individuals and as groups, listening to the stories they told about their work and lives in a particular context (p. 359). And, as Witherell and Doddings (1991) found, narrative inquiries in teaching enable us to bring together a range of work, ideas and strategies on ways of knowing, telling and enacting caring relationships. The richness of the data in this approach enabled the participants to identify inhibiting factors that could contribute to stress and burnout and then to consider enabling strategies that would promote positive wellbeing in a professional setting.

\section{Beginning teachers' inhibiting factors}

The inhibiting factors identified by this group of beginning teachers were largely due to the physical demands of teaching, personal issues or workplace-related factors.

\section{Physical demands of teaching}

The beginning teachers talked about transition from university to teaching as an anxious time that impacted on their level of wellness. Factors that contributed to their changed level of wellness included:

- $\quad$ increased workload where many more hours were spent outside the normal school day preparing for teaching;

- $\quad$ physical tiredness;

- $\quad$ general voice problems;

- $\quad$ stress from dealing with additional issues like disorderly classrooms, negative school culture and having to multi-task;

- $\quad$ inadequate time for eating and toilet breaks;

- $\quad$ less available time to attend regular gym or sports training; and

- $\quad$ emotional tiredness caused by professional conflicts between their values and beliefs and those of the school community.

Fatigue, illness, mental problems, anxiety, anger, isolation, intolerance and loneliness have been identified as contributing factors to teacher stress. These can sometimes make teachers susceptible to illness and other related health risks (Crute 2007; Neville 2006; Thornton 2004); and cause physical and mental exhaustion 
(Evers, Tomic and Brouwers 2004; Pillay et al. 2005). In this study, beginning teachers felt physically sick; tired from lack of sleep; physically unhealthy through a lack of time to exercise and cook healthy meals; unmotivated; run down; and sometimes depressed, which caused unhealthy eating, lethargy, longer term illness and health risks. Frustration at being time poor was the major concern because this manifested itself in less time for fitness and maintaining a healthy lifestyle which, for some, led to physical and mental exhaustion. This was exacerbated for those in isolated environs, as this participant shared:

I found I had limited time to attend a regular gym or football training and therefore there was a reduction in my amount of exercise. And teaching in the country - I had to leave friends and family. There were daily emotional highs and lows.

Beginning teachers expressed an awareness of their poor health and wellbeing, which was exacerbated by drinking too much coffee or alcohol, being tired due to sleep deprivation or anxiety, and feeling depressed.

\section{Personal issues}

Beginning teachers experienced additional burdens to those of more experienced teachers. These were often personal issues brought about because they set high expectations caused by added pressure placed on them to achieve and to 'get it right' all of the time; by the struggle to find a work-life equilibrium; by trying to meet society's perception of a 'good' teacher; by managing changing multidimensional roles; and by the need to appear confident to others. These experiences were further amplified because the beginning teachers were working in new environments where they had to build new relationships with students, teachers and parents/carers, at the same time as they grappled with the demands of the curriculum and managing student behaviour. As one beginning teacher stated,

I felt overwhelmed with learning and workload. I had a fear that my students would fail. There was self-doubt about being an effective teacher and I was spending too much time on lesson plans - to the detriment of social relationships with family and friends.

The beginning teachers in this study said that they tried to cope on their own, in their own classrooms and in the school, but that this often created additional anxiety and pressure. They found that work became emotionally draining because of having to deal with student and family concerns, the politics of the workplace and the need to reflect on their own performance whilst developing a teacher identity. One participant reported 'feeling unsupported, unaccepted. I had a fear of violence at my school, and my anxiety impairs my ability to perceive a situation logically.' A familiar complaint was that 'I was not looking after myself. I was taking on too much. I was thinking you can do it all yourself.' Another commented that as a preservice teacher they had not realised the extent of the emotional demands of the job. Working in an isolated environment (like a rural setting) meant that some beginning teachers were away from familial support structures. This beginning teacher reflected that beginning teachers were not equipped with emotional strategies like coping, autonomy, self-development, and the skills to counsel students and parents. Beginning teachers in other schools experienced feelings of isolation because they 
were too busy to talk to other teachers, to get their opinions and perspectives heard, and were not confident to discuss what worried them. The beginning teachers realised that exhaustion impacted on their emotional resilience and cognitive functioning, and that social interactions and depersonalisation led to isolation and potential loss of faith in self and the world. Pillay et al. (2005), who researched the first 12 months of a teaching career, stated that a reduced sense of personal accomplishment may bring on lessening self-esteem and self-efficacy and ineffective cognitive patterns.

Both internal (related to the school or classroom environment) and external (where issues arose related to the community, the socioeconomic status or political make-up of the area, specific family structures, and individual characteristics of community members) factors contributed to this state. Sometimes the participants felt they were unprepared for these variances in school and student clientele, which were worse for temporary relief teachers (daily relief teachers who teach on demand) who felt a lack of connection with community, and lack of sufficient support in the initial years of employment. Overriding these feelings was also the deficit attitude towards 'new' teachers, often perpetuated in the media, fuelling further unrealistic expectations of them.

\section{Workplace-related factors}

The places where the beginning teachers sought employment contributed to these physical and personal issues: the perceived increase in, and complexity of, teachers' workload affected many of the new beginning teachers; as did a culture of negativity; feeling overwhelmed or lacking confidence; having to deal with frequent 'difficult' situations; and the amount of time needed for planning and preparation, especially when they had to teach subjects they were not trained for, which caused them to feel inadequate and undervalued. Some realised that the rewards for teaching did not match their efforts and the demands had also increased or changed in recent years, making the learning curve for new teachers extremely challenging (Goddard and O’Brien 2003).

The beginning teachers also felt that the level of responsibility changed when they transitioned from pre-service teacher to teacher. They mentioned that they were required to have extensive content knowledge in order to teach effectively. But what was more demanding for them was the need to cater for diverse family and cultural contexts in the curriculum. These 'add-ons' did not fit neatly into the required areas of learning and involved higher emotional involvement because of the need to adhere to legislative guidelines, administrative matters and parent meetings. Despite their own level of personal unwellness as beginning teachers, many felt more concerned about student wellbeing, acknowledging that some schools felt like they were becoming the dumping ground for issues that did not fit neatly into the core curriculum. There also appeared to be a mismatch between the teachers' desire for student success and the actual outcomes. They held high expectations for their students, which led to mixed feelings about their teaching capabilities, a situation that Goddard and O’Brien (2003) stated forces new teachers to prove themselves as worthy and credible. 
The apparent transformation of teachers' work contributed to their stress levels. The transformation included increased levels of administrative paperwork, a breakdown in discipline, media criticism, new assessment procedures and curriculum innovations, parent and community expectations, increased workload pressures, lack of influence over decision making, and inadequate salary. One beginning teacher documents this:

Information technology advances; dealing with students, parents, staff, community; learning new information (curriculum and pedagogy) and skills; ineffective staff relationships; low levels of collegial support; role conflict; teacher relocation; lack of leadership support and recognition, particularly with adapting to site, state and national changes; student behavioural problems; and inadequate resources.

Another beginning teacher mentioned that 'classes are too large, there are poor working conditions and classroom infrastructure is dull or inadequate - making it very hard to rock up every day and be excited about teaching'. From a systemic viewpoint, central policies and procedures were not adhered to consistently or conflicted with personal values and beliefs (e.g. behaviour management), were too rigid, and the schools failed to acknowledge teachers' concerns or review policies.

Contract teachers (those employed for short periods) experienced additional burdens to wellbeing, as there is

insufficient time to get to know children, poor parent perception of contract teachers, limited social connections within the school, lack of assistance, high cognitive load, learning the specifics of the school and classes (rosters, subject areas), memory overload (student names), poor salaries, lack of job flexibility, public pressure, budget cuts, excessive paperwork and testing, demanding student and parent behaviour.

This study has identified a number of inhibiting factors for beginning teachers that impact on teachers' working and personal lives, inadvertently affecting the wellbeing of the students they teach. The participants in this study showed acute awareness of these issues and were able to identify strategies that could address many of the inhibiting factors. We refer to these as enabling factors and will demonstrate how personal wellbeing transpires when all five dimensions of wellbeing coincide.

\section{Beginning teachers' enabling strategies}

Patterson, Collins and Abbott (2004) profess that a healthy balance between work and personal lives is developed by teacher resilience, having collegial support, regular professional development, working with others who have similar values and beliefs, valuing positive relationships with others that promote teacher learning, and developing teacher confidence. The beginning teachers recognised the importance of these elements and suggested practical strategies:

- $\quad$ setting up the classroom to achieve a good working space;

- $\quad$ allocating tasks so responsibility is shared; 
- $\quad$ establishing behavioural boundaries within the classroom;

- $\quad$ attending to light and room temperature;

- establishing a positive, bright, cheerful, inviting environment in the classroom and staffroom;

- $\quad$ knowing and working within the school policies;

- managing personal time, setting priorities and avoiding work overload; and

- $\quad$ planning lessons to meet learner needs.

They identified specific experiences, qualities and ideas according to the five dimensions of wellbeing and spanned individual, classroom, school, community and professional fields, which indicated that the beginning teachers were aware of the holistic nature of wellbeing and the importance of stakeholders working together to achieve this.

The beginning teachers acknowledged the importance of the physical dimension and maintaining a fit and healthy lifestyle. They were frustrated when their physical regime was interrupted by isolation or the demands of the job, but they were able to provide extensive practical strategies that would enhance teaching for young learners in the classroom as well as model good wellbeing practices across the whole school and the community. They reported that certain experiences were required if physical wellbeing was to be achieved, like having a healthy and nutritious diet, regular sleep, a regular fitness program, consistent body weight, 'down time', and regulating potential harm to their bodies caused by teaching, like voice care.

We identified certain qualities in the beginning teachers who reported a good sense of wellbeing. These were positive thinking about the demands of the job, the importance of being a positive role model to others, a set of realistic coping strategies for the times when things went wrong, and the confidence to ask for help.

However, a significant recurring theme for the beginning teachers was the realistic awareness of the lessened time available to them, particularly in the initial stages of their career. Integrating the physical and cognitive wellbeing dimensions with the intellectual demands of school policies and procedures was vital, and was achieved by integrating exercise and healthy eating. Ideas for beginning teachers included incorporating relaxation activities into daily regimes, using professional services for support, and ensuring that the classroom space was safe, both physically and emotionally.

Emotional and social strategies were interlinked, as the beginning teachers acknowledged that a positive emotional state was enhanced if individuals had a balance of social activities in their personal or work lives. They valued socialising with colleagues and working in teams as the means to develop collaborative working 
relations that promoted networks of emotional support. These also contributed to the development of a positive learning community that was inclusive of the learners in their classes, carers, the wider community and the leadership group.

Another prominent enabling strategy described by beginning teachers was the inclusion of the voice of members of the school community in contributing to decision making, policy development and school activities. This promoted a sense of belonging, value, mutual respect and collegiality within the community. They identified working with others in programming, assessment and reporting as opportunities to acknowledge skills, celebrate achievements, share resources, and build professional and personal relationships. Preparation, organisation, prioritisation and setting realistic goals were described as key factors to avoiding stress. The impact of a poor emotional state, which could produce stress, burnout and ultimately mental illness, meant that the beginning teachers should involve the employer and professional associations in the management of their stress levels to ensure that support was available. At the micro level, beginning teachers prioritised establishing a healthy classroom to ensure that both teacher and children were working in a happy, safe and welcoming learning environment in which they felt connected. It was important to display work, open windows, have a clean, spacious, nice smelling classroom, play music, and have visual aids.

The beginning teachers highlighted building relationships with students, parents and community members as a vital ingredient in the social and emotional space. These relationships were typified by being an active listener and open communicator, which was sometimes implemented through various means including social networking sites. Initiatives that promote lifelong learning include being active as a volunteer, and being engaged in after school sports and extracurricular activities. Socialising during leisure time was seen as a worthwhile experience that helped to develop qualities like respect, teamwork, a connection with others and social competence skills (empathy, sympathy and genuineness). Most importantly, they saw family and friends as integral to maintaining and promoting social and emotional wellbeing.

The teachers saw the importance of maintaining study, professional development, training and inquiry into one's practice as contributions to cognitive wellbeing. The beginning teachers acknowledged that being planned and well organised for daily teaching, supported by the skills of flexibility and adaptability, were essential survival strategies for the classroom. McDonald stated:

One of the best ways to lower the amount of stress you deal with on a daily basis is to be prepared. Some of that preparation requires organisation. Preparation is absolutely the key to being a successful teacher. The more thought and effort you put into your lessons and your job, the better you will be. You will also be less stressed throughout the year. (2006, p. 25)

Experiences of cognitive wellbeing used effectively by this group of beginning teachers included the monitoring and prioritising of workload, keeping the brain active, setting achievable long- and short-term goals, reviewing these goals, and participating in research opportunities. Having colleagues they could 'get along well 
with' was seen as important by one participant who also stated: 'keeping motivated and curious, taking risks, experimenting with new ideas, attending professional development, doing further study, and research and inquiry projects'. These were all elements that they perceived as enabling cognitive wellbeing strategies, particularly as part of a whole-school learning community. Examples of specific cognitive skills that could enhance wellbeing were engaging in activities that enhanced memory and problem solving, completing tasks that involved information processing, doing puzzles, conducting inquiries into teaching and learning, thinking laterally, and being committed to lifelong learning.

One participant advised:

Ask yourself 'What's the worst that can happen?' Make a list of your own strengths and accomplishments and refer to it to boost confidence. Don't waste energy worrying. Take action on what you can control and minimise risks for what you don't.

This beginning teacher showed a relaxed yet positive attitude to the demands of her teaching experience and was quite realistic. This example of spiritual wellbeing was included in the beginning teachers' list of strategies, which also included maintaining a journal as an effective reflective activity, relaxing activities like meditation and yoga that helped to focus or re-focus oneself, and calm environments that sometimes included music, soft voices or elements of the outdoors. Teachers who could set goals, reflect, take 'time-out' and relax demonstrated spiritual qualities that augured well for their overall wellbeing. Connectedness and a sense of belonging were essential for spiritual wellbeing and were developed by working alongside others with a common purpose whilst respecting differing values and beliefs. Having time to relax and reflect promoted a positive identity, self-esteem and connectedness to one's own feelings. Beginning teachers described incorporating spiritual wellbeing into school policy and procedures including school values and ethos statements as enabling strategies in establishing a learning community where all members felt safe and had a sense of belonging.

This group of beginning teachers believed that the multidimensional nature of all of these wellbeing strategies would contribute to their retention in teaching. However, the summary of all of the strategies indicates that beginning teachers must also have a capacity to take action against inhibiting factors. These may include:

- $\quad$ having positive self-esteem and self-efficacy;

- $\quad$ taking an active stance towards obstacles;

- developing the ability to see a difficulty as a problem that can be worked on, overcome, changed, endured or resolved;

- $\quad$ having a level of reasonable persistence; and

- developing a range of strategies and skills to bear on problems in flexible ways. 
Beginning teachers who acknowledged they had positive wellbeing demonstrated that they also had personal and professional protective qualities that influenced their state of competence. These included social competence, problem-solving strategies, autonomy, a futures perspective, hope and feelings of belonging to a team that shared a common purpose. These qualities allow teachers to display wellbeing, which ensures that learners in their classrooms benefit from this level of wellness.

\section{Summary}

In this paper we have argued that beginning teachers must adopt enabling wellbeing strategies if they are to be retained as effective practitioners and as role models that contribute to the wellbeing of future generations. We suggest that wellbeing is developmental and individualised, which is particularly pertinent to beginning teachers as it implies the promotion of positive personal and physical identities as well as a sense of belonging, and it also provides teachers with a sense of empowerment in their new role. The community, school leaders and employers are instrumental in helping to raise awareness, and to establish and maintain positive workplace practices that foster working and learning conditions appropriate for the development of wellbeing for future teachers and leaders. This holistic approach emphasises how social and cultural forces shape individual and group identities, an important characteristic of long-term happiness, growth, sustainability and satisfaction in the teaching profession.

\section{References}

Berman, JA 1989, 'Person characteristics and the perception of organization and climate’, International Journal of Value-Based Management, vol. 2, no. 2, pp. 101-110.

Bernard, M, Stephanou, A and Urbach, D 2007, ASG student social and emotional health report, ACER, Melbourne.

Butt, R and Retallick, J 2002, 'Professional well-being and learning: a study of administrator-teacher workplace relationships', Journal of Educational Enquiry, vol. 3, no. 1, pp. 17-34.

Clandinin, DJ (ed.) 2007, Handbook of narrative inquiry: mapping a methodology, Sage, Thousand Oaks, CA.

Crute, S 2007, ‘Don’t lose your head’, NEA Today, vol. 25, no. 5, p. 46.

Cummins, R, Eckersley, R, Pallant, J and Okerstrom, M 2002, The impact of personal relationships and household structure on the wellbeing of Australians, Australian Unity Wellbeing Index Report, Australian Centre on Quality of Life, Deakin University, Melbourne. 
Department of Education and Children's Services (DECS) 2007, Learner wellbeing framework for birth to Year 12, DECS, Adelaide.

Evers, WJ, Tomic, W and Brouwers, A 2004, 'Burnout among teachers: students' and teachers' perceptions compared', School Psychology International, vol. 25, no. 2, pp. 131-148.

Goddard, R and O’Brien, P 2003, 'Beginning teacher perceptions of their work, well-being and intention to leave', Asia Pacific Journal of Teacher Education and Development, vol. 6, no. 2, pp. 99-188.

Hakanen, JJ, Bakker, AB and Schaufeli, WB 2006, 'Burnout and work engagement among teachers’, Journal of Social Psychology, vol. 43, pp. 495-513.

Hart, PM, Wearing, AJ, Conn, M, Carter, NL and Dingle, RK 2000, 'Development of the school organisational health questionnaire: a measure for assessing teacher morale and school organisational climate', British Journal of Educational Psychology, vol. 70, pp. 211-228.

Holmes, E 2005, Teacher wellbeing: looking after yourself and your career in the classroom, Taylor \& Francis, London.

Hugo, G 2007, 'Attracting, retaining and empowering quality teachers: a demographic perspective’, Kevin Majoribanks Memorial Public Lecture. University of Adelaide, Adelaide, 4 October.

Johnson, M 1987, The body in the mind: the bodily basis of meaning, imagination, and reason, University of Chicago Press, Chicago.

Lantieri, L and Nambiar, M 2004, 'Sustaining the soul that serves: healing from within’, Reclaiming Children and Youth, vol. 13, no. 2, pp. 120-125.

Leggo, C 2005, 'The heart of pedagogy: on poetic knowing and living', Teachers and Teaching: Theory and Practice, vol. 11, no. 5, pp. 435-455.

Louden, W 2008, '101 damnations: the persistence of criticism and the absence of evidence about teacher education in Australia', Teachers and Teaching, vol. 14, no. 4, pp. 357-368.

McDonald, E 2006, 'Ease stress by being prepared', Education Horizons, vol. 9, no. 3, pp. 25-26.

Moon, B 2007, Research analysis: attracting, developing and retaining effective teachers: a global overview of current policies and practices, United Nations Educational, Scientific and Cultural Organization, Paris.

Neville, K 2006 'Can food and supplements help you de-stress? EN’s 8 essentials to try’, Environmental Nutrition, vol. 29, no. 11, pp. 1, 6. 
Patterson, J, Collins, L and Abbott, G 2004, 'A study of teacher resilience in urban schools’, Journal of Instructional Psychology, vol. 7, no. 4, pp. 256-264.

Pillay, H, Goddard, R and Wilss, L 2005, 'Well-being, burnout and competence: implications for teachers', Australian Journal of Teacher Education, vol. 30, no. 2, pp. 22-33.

Rogers, AR 1980, 'The domain of health: a conceptual model outlining the scope, direction and impact of health education', paper presented at the Annual Convention of the American Alliance for Health, Physical Education, Recreation, and Dance, Detroit, MI, 13 April.

Ross, A and Hutchings, M 2003, Attracting, developing and retaining effective teachers in the UK and Northern Ireland: OECD country background report, Institute for Policy Studies in Education, London.

Thornton, P 2004, Understanding and coping with stress in teaching, Coolabah, Tamworth, NSW.

Van Petegem, K, Creemers, BPM, Rosseel, Y and Aelterman, A 2006, 'Relationships between teacher characteristics, interpersonal teacher behaviour and teacher wellbeing', Journal of Classroom Interaction, vol. 40, no. 2, pp. 34-43.

White, R and Wyn, J 2008, Youth and society: exploring the social dynamics of youth experience, Oxford University Press, Victoria.

Wilber, K 2000, 'Waves, streams, states and self: further considerations for an integral theory of consciousness', Journal of Consciousness Studies, vol. 7, no. $11 / 12$, pp. $145-176$.

Witherell, C and Doddings, N 1991, Stories, lives, tell: narrative and dialogue in education, Teachers College Press, New York.

Wyn, J 2007, 'Learning to "become somebody well”: challenges for educational policy’, Australian Educational Researcher, vol. 34, no. 3, pp. 35-52.

Wyn, J 2009, Youth health and welfare: the cultural politics of education and wellbeing, Oxford University Press, South Melbourne.

Yong, Z and Yue, Y 2007, 'Causes for burnout among secondary and elementary school teachers and preventative strategies', Chinese Education and Society, vol. 40, no. 5, pp. 78-85. 